\title{
Performance Analysis of Steel Scrap in Structural Concrete
}

\author{
Abdul Rahman ${ }^{1}$, Syed Mustafa $\mathrm{Ali}^{2}$, Syed Azeemuddin ${ }^{3}$, \\ Syed Noman Hussain ${ }^{4}$, Syed Mustafa Ali ${ }^{5}$ \\ 1, 2, 3, 4, 5 (Civil, Lords Institute of Engineering and Technology, India) \\ Projects Coordinator \& Guide: Ashwin R, \\ MD Safiuddin ,Head of Civil Engineering Department
}

\begin{abstract}
This project work emphasis on the study of using steel scrap and manufacture sand in the innovative construction industry. "Steel scrap" concrete is a concrete containing fibrous material that is uniformly distributed and casually oriented. The steel scrap waste material which is obtainable from the lathe can be used as steel fiber for the innovative construction industry and in pavement construction. It is generated by each lathe industries Dumping of these wastes contaminates the soil and groundwater, which creates a harmful environment. In addition, to get sustainable development and environmental benefits, lathe scrap with concrete is likely to be used. In this project steel scrap concrete using lathe waste is prepared and its properties are studied. "Manufactured sand" is such alternative for good quality Natural River sand due to depletion of resources and restriction due to environmental consideration has made concrete manufacturers look for suitable alternative fine aggregate. Though it has been in use in concrete manufacturing in India, the percentage of its contribution is still very negligible in many parts of the country. The tests conducted were slump test, compressive strength test, split tensile strength test and. For this concrete cubes, beams and cylinders were cast and cured and tests were done at 3th day, 7th day and 28th day.
\end{abstract}

Keywords: Steel Scrap, Manufacture sand, Compressive strength, Tensile strength and Carbonation test.

\section{Introduction}

Water is the most consumed resource by humans since time immemorial and only second to it is the highly vital concrete. Modern architectural marvels and building structures require challenging construction methods and inventions. So, it becomes imperative to have concrete that has extreme strength yet enough physical properties to make it workable. When we speak of compressive strength of concrete, it is quite high but tensile strength becomes low. When we use steel reinforcement the tensile strength of concrete increases considerably.Research followed by technological developments have enlightened us with ways to add fiber to strengthen concrete. To develop specialized concrete lots of efforts are being in this field. Attempts are being made by worldwide researchers to effectively enhance the performance of concrete by using admixtures and fibers in certain proportions. Recently we have begun using lathe waste material that is locally available which has become an important part in construction. Fiber reinforced concrete usage has been amplified by the day particularly due to the introduction of steel fiber to cement concrete which has led to an incredible improvement in usability properties of concrete. One ton of carbon dioxide is released into the atmosphere by the production of a single ton of cement. Similar damage to the environment is done by the steel industry. To avoid such staggering quantities of generated wastes we need to reuse it by pondering over sustainable development. At present, we are faced with expensive options in the market when it comes to purchase of different categories of steel fiber. Lots of local workshops and lathes offer low cost lathe scraps in plentitude. Lathe industries[1] generate daily approximately $20 \mathrm{~kg}$ lathe waste and heavily contaminate the ground water and soil by dumping in the barren lands. Effective[2] management of waste steel scrap material derived from lathe to be used as steel fiber is among the finest solutions for civil construction like pavements and other structures;[3] this recycles the lathe scrap with concrete. The objective of this paper is to do a comparative study of plain concrete and lathe fiber reinforced concrete. Research followed by experiments and investigations are inevitably necessary to learn details of both plain and steel fiber reinforced concrete when they are fresh and hardened respectively. Various improvements in properties are noted by the addition of fiber such as crack resistance and prevention of crack propagation, modulus of elasticity, shrinkage reduction and toughness.

The main objectives of this paper are:

- To explore and study the use of lathe scraps as fiber in concrete.

- To compare proportions and percentages of lathe fibers in concrete and study their effects. 


\section{Literature Review}

In today's technologically advanced world we can find concrete very easily at lower costs compared to before. It is one of the most adaptable and flexible building materials available which can be molded to fit into any column or rectangular beam as well as a cylindrical tank of water storage. High rise buildings and any structural shapes from the ordinary to the extraordinary can be built. The need for reinforcing concrete is due to the weak tensile strength even though under compression concrete is very strong. Hence, we use many forms of reinforcement; the most common being steel bars. As with every boon of modern civilization we must deal with the pros and cons of concrete too. Some of the disadvantages are low tensile strength and formwork requirement. Its primary benefits are its high water and fire resistance and compressive strength with a very good service life and low maintenance. Concrete has its drawback in relatively low strength per unit weight. Concrete's tensile strength is characteristically $8-15 \%$ of its compressive strength. This limitation has been dealt with by engineers in recent and past times by utilizing rebar's (reinforcing bars) to create reinforced concrete. The purpose of this is to benefit from the resistance that rebar's have over tensile and shear stresses and the resistance of concrete over compressive stresses. A beam has a longitudinal rebar which resists flexure (tensile stress) while the stirrups enveloping the longitudinal bar hold the bar in position in addition to resisting shear stresses. When we speak of vertical bars in a column, they are resistant to buckling and compression stresses while the ties provide confinement to vertical bars along with resisting shear. Reinforced concrete structures are susceptible to cracks which flow freely until they meet a rebar. Therefore, we need closely paced tightly held reinforced concrete which should also be multidirectional. Concrete[4] needs addition of fiber to control its cracking produced by drying shrinkage as well as plastic shrinkage. Permeability i.e. water that bleeds from concrete is also reduced. There are few varieties of fiber that produce shatter and abrasion resistant concrete which has huge impact on construction. Normally we find that the flexural strength of concrete is not increased by fibers and hence they cannot be thought of as a full-fledged replacement of structural steel reinforcement. Fiber has a property which is modulus of elasticity; if this is seen to be higher than the matrix (mortar or concrete binder) then it assists in carrying the load by increasing material strength. Nevertheless, very long fibers naturally tend to form 'balls' in the mix hence leading to difficulties in effective operations.

\subsection{M-Sand (Manufacturing Sand)}

This is a material acquired from quarries after extract ion and processing of rocks. So it is used as fine aggregate concrete which is produced from quarry stone has obtained by crushing or grinding \& classification of grading zone of sand needs to be tested. To test that, sieve analysis needs to be done. In this process (M-sand) is passed through the 4.75 (IS) accommodating to grading zoneII.

There are differences between natural sand and (m-sand). Natural sand is more rounded because of weathering but (M-sand) contain more angular particles when compared to natural sand. According to some recent experiments the rough surface of the ( $\mathrm{m}$-sand) which contain angular particles has shown positive effects which is used in fresh concrete and shows better workability and finish ability.

Technical requisites needs to be compared between natural sand \& manufacturing sand. Strength and durability of concrete needs to be satisfied to produce concrete in an economical way it has become necessary to check the suitability.

Due to fast growing industry, The demand for sand has increased. (M-sand) is a substitute for river sand to balance the economic strength in construction. (M-sand) is a rock powder produced by crushing the rocks, which are cubical in shape with grounded borders, Get cleaned \& graded form material to be used as construction, Size of (M-sand) is less than $4.75 \mathrm{~mm}$

Manufactured sand is an another available possibilities for river sand due to fast increase of construction industry.

Usage of sand has increased at very great amount causing shortage of appropriate river sand in most part of the world. Due to availability and reduced transportation costs, Usage of (M-sand) has been increased compared to river sand \& because of reduction in good quality river sand, usage of (M-sand)has increased and can easily found at nearby places.

Purpose \& Uses:

- Increases the thickness of concrete, thus reduces the cost

- supply dimensional stability

- develops hardness, abrasion resistance, elastic modulus and other properties which make concrete more durable, strong and cheaper.

\section{Research Methodology}

In the present work, experimental researches were carried out to know how effectively we can replace cement concrete constituents.A complete explanation of the methodology followed in the present researches are discussed below. The first chapter demand collection and studying the physical properties of cement, M-sand, 
steel scrap waste and coarse aggregates. M-sand is acquired from local quarry. Coarse aggregate passing IS 20 $\mathrm{mm}$ sieve and retained on IS $12.5 \mathrm{~mm}$ sieve was considered for experimental program. M-sand were used to prepare concrete.

Tests conducted on M-sand.

- Specific gravity

- Grain size distribution

- Fineness modulus

- Moisture content

The second phase involves casting of specimens, conducting tests and to know the potential of use of such modified concretes.

\section{Materials Used}

Materials[6] consist of cement, M-sand, coarse aggregate, steel scarp waste and water.

\subsection{Cement}

Ordinary Portland Jaypee Cement 53-Grade -----IS 12269:1987.Chemical and Physical properties of cement are as shown in Table1.

\subsection{M-Sand}

Manufacturing sand (M sand) passing through $4.75 \mathrm{~mm}$ IS sieve conforming to grading zone II was used. Sieve analysis was done to find out the grading zone. The Properties like fineness modulus3.38, specific gravity-2.5, bulk $1725 \mathrm{~kg} / \mathrm{m} 3$ and satisfied the requirements of IS 383-1970.As shown in the Table2. Material is shown in Fig1.

\subsection{Coarse Aggregate}

Crushed stone aggregate with particle size less than $20 \mathrm{~mm}$ size were used for present investigation. Samples were tested as per IS: 2386-1997.As shown in the Table3.

\subsection{Steel Scrap Waste}

Lathe waste is a material from lathe machines and that can be used as steel fibers. But the aspect ratio was not always constant. Here manually processed lathe waste aspect ratio varying from 45 to 100 is used. The thickness varies from 0.3 to $0.75 \mathrm{~mm}$ and length from $25 \mathrm{~mm}$ to $40 \mathrm{~mm}$. As shown in the Table4. Material is shown in Fig2.

\subsection{Carbonation Test}

Carbonation of concrete involves a physiochemical reaction between atmospheric carbon dioxide and the calcium hydroxide generated in cement hydration. The precipitation of calcium carbonate as shown in the following equation reduces the $\mathrm{pH}$ level of concrete:

$$
\mathrm{Ca}(\mathrm{OH})_{2}+\mathrm{CO}_{2} \rightarrow \mathrm{CaCO}_{3}+\mathrm{H}_{2} \mathrm{O} \text {. }
$$

Using a phenolphthalein indicator solution to monitor carbonation depths has been well documented and is convenient. The solution is a colorless acid=base indicator, which turns purple when the $\mathrm{pH}$ is above 9, denoting the presence of $\mathrm{Ca}(\mathrm{OH})_{2}$. As shown in the Fig6.

\subsection{Mix Design}

In the[7] present study M30 grade concrete mix design as per IS: 10262-2009 is carried out. The concrete mix proportion was 1:1.7:2.3 and water content was $197 \mathrm{~kg} / \mathrm{m}^{3}$. As shown in the Table 5 .

Figures and Tables

Table 1: Chemical and Physical properties of cement

\begin{tabular}{|l|l|l|l|}
\hline & Particulars & $\begin{array}{l}\text { Test Results } \\
\text { Obtained }\end{array}$ & $\begin{array}{l}\text { Requirement } \\
\text { IS: OPC-53 S }\end{array}$ \\
\hline & CHEMICAL PROPERTIES & & \\
\hline 1 & Lime Saturation Factor (LSF) & 0.91 & 0.80 To 1.02 \\
\hline 2 & Alumina to that of Iron oxide Ratio \% (A/F) & 1.31 & 0.66 Min. \\
\hline 3 & In soluble Residue (\% by mass) & 0.88 & 2.00 Max. \\
\hline 4 & Magnesium oxide (\% by mass) & 3.18 & 5.00 Max. \\
\hline 5 & Sulphuric Anhydride (\% by mass) & 1.86 & 5.00 Max. \\
\hline 6 & Total Loss On Ignition (\% by mass) & 1.02 & 4.00 Max. \\
\hline 7 & Tricalcium Aluminate (C3A) \% & 6.98 & 10.00 Max. \\
\hline 8 & Tricalcium Silicate (C3S) \% & 49.49 & 45.00 Min. \\
\hline 9 & Total Chloride ( \% by mass) & 0.013 & 0.10 \\
& & & 0.05 Max.(For \\
\hline & PHYSICAL P.C.) & N.C.)* \\
\hline 1 & Fineness (M2/Kg) & 407 & 370 Min. \\
\hline
\end{tabular}




\begin{tabular}{|l|l|l|l|}
\hline 2 & Setting Time (Minutes) & & \\
\hline & Initial & 145 & 60 Min. \\
\hline & Final & 195 & 600 Max. \\
\hline 3 & Le. Chatelier (mm) & 1.00 & 5.00 Max. \\
\hline
\end{tabular}

Table 2: Properties of M-Sand

\begin{tabular}{|l|l|l|}
\hline S.No & Properties & values \\
\hline 1 & Fineness modulus & 3.38 \\
\hline 2 & Specific gravity & 2.5 \\
\hline 3 & Bulk density & $1725 \mathrm{~kg} / \mathrm{m}^{3}$ \\
\hline 4 & Grading & Zone II \\
\hline
\end{tabular}

Table3: Physical Properties of Coarse Aggregate

\begin{tabular}{|l|l|l|}
\hline S. No. & Property & Test Result \\
\hline 1 & Specific gravity & 2.7 \\
\hline 2 & Bulk density $\left(\mathrm{kg} / \mathrm{m}^{3}\right)$ & $1,420 \mathrm{~kg} / \mathrm{m}^{3}$ \\
\hline 3 & Fineness modulus & 7.4 \\
\hline 4 & Water absorption $(\%)$ & 0.05 \\
\hline
\end{tabular}

Table4: Properties of Scrap Steel Fiber

\begin{tabular}{|l|l|l|}
\hline S.NO. & Properties & Values \\
\hline 1. & Cross - section & Straight and deformed \\
\hline 2. & Diameter $(\mathrm{mm})$ & $0.3-0.75$ \\
\hline 3. & Length $(\mathrm{mm})$ & $25-40$ \\
\hline 4. & Density $\mathrm{kg} / \mathrm{m}^{3}$ & 7850 \\
\hline 5. & Young modulus $\left(\mathrm{N} / \mathrm{mm}^{2}\right)$ & $2 \times 10^{5}$ \\
\hline 6. & Tensile strength $\left(\mathrm{N} / \mathrm{mm}^{2}\right)$ & $500-3000$ \\
\hline 7. & Specific gravity & 7.85 \\
\hline 8. & Aspect ratio & $45-100$ \\
\hline 9. & Elongation $(\%)$ & $5-35$ \\
\hline
\end{tabular}

Table5: Mix Design Proportions

\begin{tabular}{|l|l|l|}
\hline S.No & Items & Unit Per $\mathrm{m}^{3}$ of concrete \\
\hline 1 & Cement & $430 \mathrm{~kg} / \mathrm{m}^{3}$ \\
\hline 2 & Fine Aggregate & $761.07 \mathrm{~kg}$ \\
\hline 3 & Coarse Aggregate & $1002.02 \mathrm{~kg}$ \\
\hline 4 & Water & 1971 itres \\
\hline
\end{tabular}

Fig1: Steel Scrap




Fig2: $M$ sand

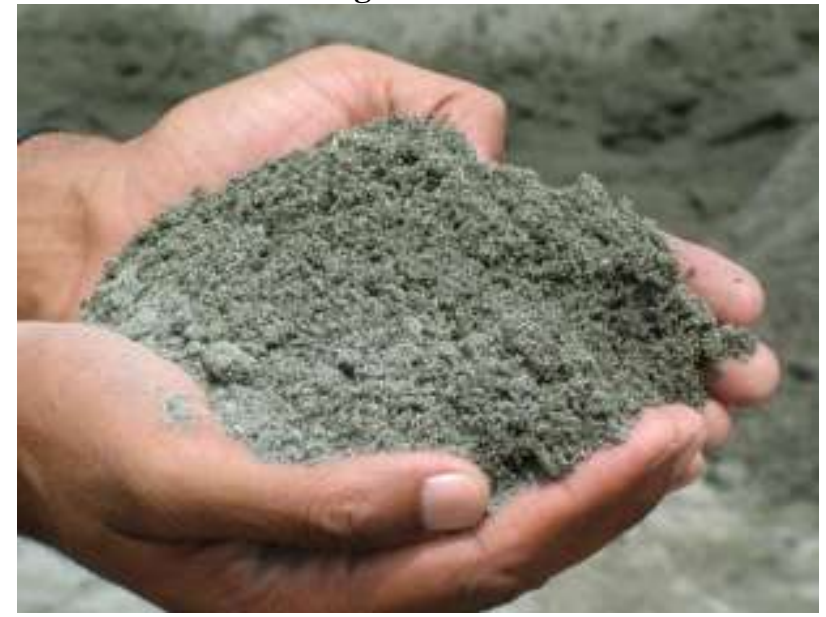

Fig 3: Sieve Analysis

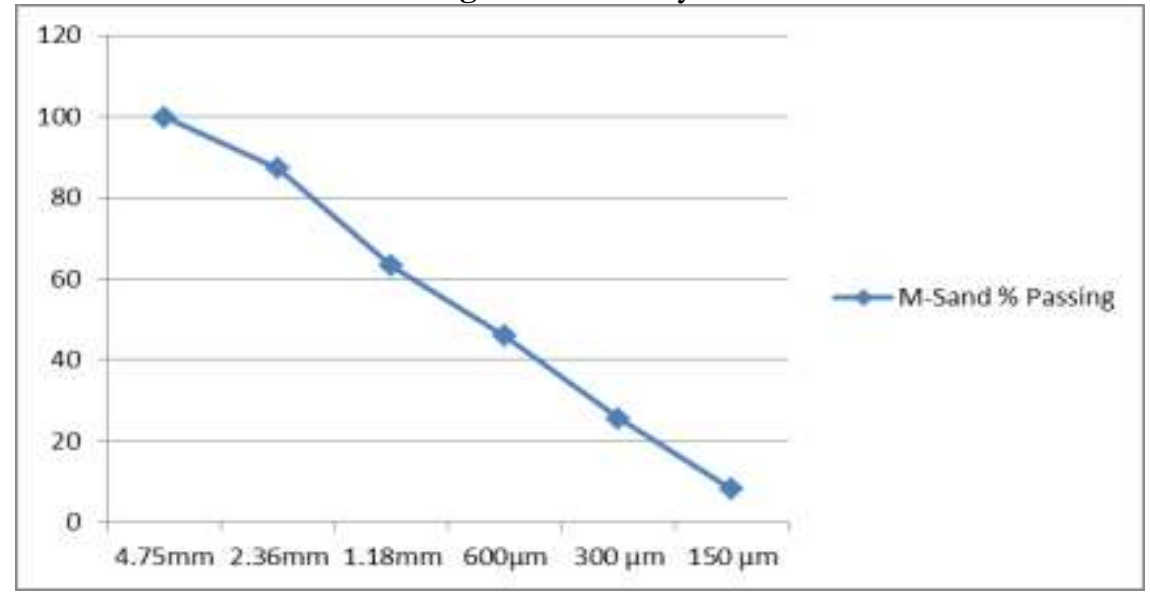

Fig 4: Compressive strength




Fig 5: Tensile strength

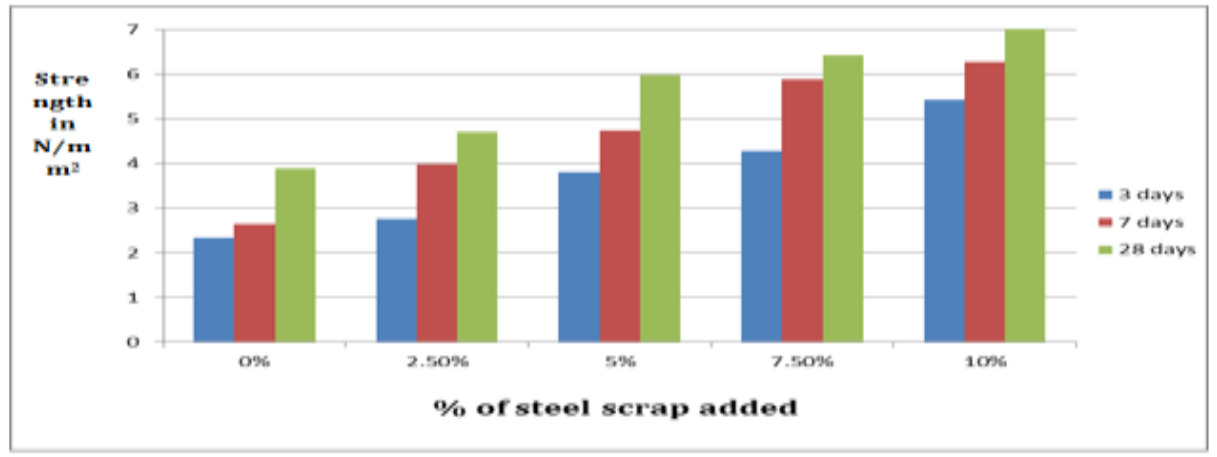

Fig 6.Carbonation Test

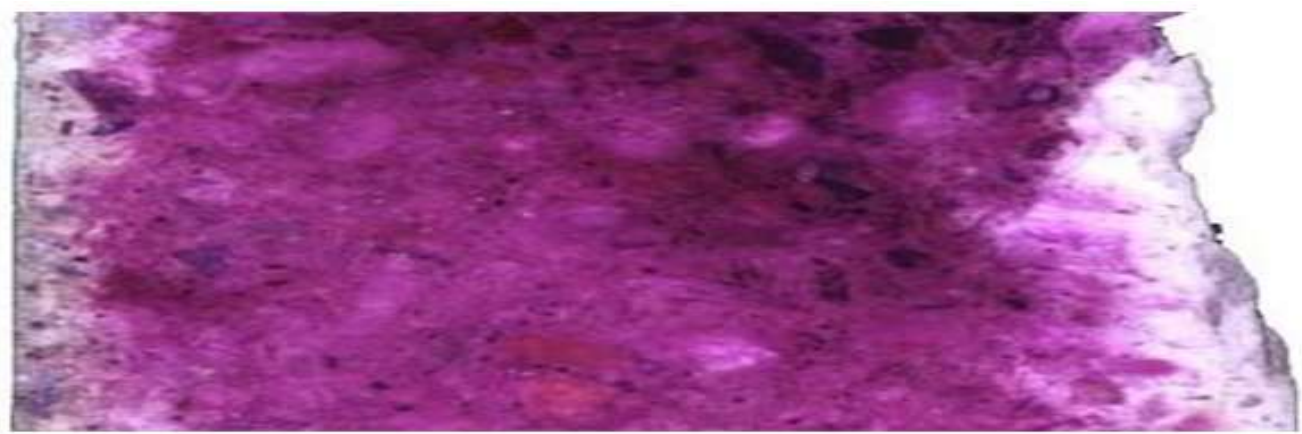

\section{Results}

In durability analysis of steel scarp waste, we conduct the compressive strength tests and tensile strength tests of duration 3days, 7days and 28days and the results which we concluded are below in Fig4 and Fig5.

\section{Discussion}

It was observed from the results that the addition of steel scrap waste to the concrete increases the properties of concrete up to a certain limit. From the investigation, it was clear that $1 \%$ steel content has a noticeable effect on the properties of concrete. Fibers added in higher volume fraction reduces workability of mixes as they clump together and tend to "ball". It results in higher presence of voids. Hence an optimum percentage of fiber content is always preferable.

\section{Conclusion}

The waste steel scrap[5] material which is available from the lathe can be used as steel fiber for innovative construction industry.

- An optimum of $1 \%$ of lathe scrap as an addition can be used to improve the strength of fiber reinforced concrete

- Compressive strength increases up to $60.171 \%$ at 28 days when compared to control specimen

- $\quad 36.904 \%$ increase in Tensile strength at 28 days when compared to control specimen

\section{References}

[1]. Aravindan, S., and Arunkumar, C.D., (2013), "Experimental Studies on Fiber Reinforced Concrete from Industrial Waste", MiddleEast Journal of Scientific Research, Vol.18, pp 1738-1744.

[2]. Ashok, S.P., Suman, S. and Chincholkar, N., (2012), "Reuse of Steel Scrap from Lathe Machine as Reinforced Material to Enhance Properties of Concrete", Global Journal of Engineering \& Application Sciences, Vol.10, pp.164-167.

[3]. Shrivastavaa, P., Joshib, Y.P., (2014), "Reuse of Lathe Waste Steel Scrap in Concrete Pavements", Journal of Engineering Research and Applications, Vol. 4, Issue 12(Part 4), pp.45-54.

[4]. Shukla, A.K., (2013), "Application of CNC Waste with Recycled Aggregate in Concrete Mix", International Journal of Engineering Research and Applications (IJERA) ISSN: 2248-9622, Vol. 3, Issue 4, pp 1026-1031.

[5]. Vijayakumar, G., Senthilnathan, P., Pandurangan, K. and G Ramakrishna, (2012), "Impact and Energy Absorption Characteristics of Lathe Scrap Reinforced Concrete", International Journal of Structural and Civil Engineering Research (IJSCER) ISSN 2319 6009, Vol. 1, No. 1, pp 60-66.

[6]. IS: 383-1970, Specifications for coarse and fine aggregates from natural sources for concrete, Bureau of Indian Standards, New Delhi, India.

[7]. IS: 10262-1982, recommended guidelines for concrete mix design, Bureau of Indian Standards, New Delhi, India. 